\title{
High performance of treated and washed MSWI bottom ash granulates as natural aggregate replacement within earth- moist concrete
}

\author{
Citation for published version (APA): \\ Keulen, A., van Zomeren, A., Harpe, P., Aarnink, W., Simons, H. A. E., \& Brouwers, H. J. H. (2016). High \\ performance of treated and washed MSWI bottom ash granulates as natural aggregate replacement within \\ earth-moist concrete. Waste Management, 49, 83-95. https://doi.org/10.1016/j.wasman.2016.01.010
}

\section{Document license: \\ TAVERNE}

DOI:

10.1016/j.wasman.2016.01.010

Document status and date:

Published: 05/02/2016

\section{Document Version:}

Publisher's PDF, also known as Version of Record (includes final page, issue and volume numbers)

\section{Please check the document version of this publication:}

- A submitted manuscript is the version of the article upon submission and before peer-review. There can be important differences between the submitted version and the official published version of record. People interested in the research are advised to contact the author for the final version of the publication, or visit the $\mathrm{DOI}$ to the publisher's website.

- The final author version and the galley proof are versions of the publication after peer review.

- The final published version features the final layout of the paper including the volume, issue and page numbers.

Link to publication

\footnotetext{
General rights

- You may freely distribute the URL identifying the publication in the public portal. follow below link for the End User Agreement:

www.tue.nl/taverne

\section{Take down policy}

If you believe that this document breaches copyright please contact us at:

openaccess@tue.nl

providing details and we will investigate your claim.
}

Copyright and moral rights for the publications made accessible in the public portal are retained by the authors and/or other copyright owners and it is a condition of accessing publications that users recognise and abide by the legal requirements associated with these rights.

- Users may download and print one copy of any publication from the public portal for the purpose of private study or research.

- You may not further distribute the material or use it for any profit-making activity or commercial gain

If the publication is distributed under the terms of Article $25 \mathrm{fa}$ of the Dutch Copyright Act, indicated by the "Taverne" license above, please 


\title{
High performance of treated and washed MSWI bottom ash granulates as natural aggregate replacement within earth-moist concrete
}

\author{
A. Keulen ${ }^{\mathrm{a}, \mathrm{b}, *}$, A. van Zomeren ${ }^{\mathrm{c}}$, P. Harpe ${ }^{\mathrm{d}}$, W. Aarnink ${ }^{\mathrm{b}}$, H.A.E. Simons ${ }^{\mathrm{e}}$, H.J.H. Brouwers ${ }^{\mathrm{a}}$ \\ ${ }^{a}$ Eindhoven University of Technology, Department of the Built Environment, Eindhoven, The Netherlands \\ ${ }^{\mathrm{b}}$ Van Gansewinkel Minerals, Eindhoven, The Netherlands \\ ${ }^{\mathrm{C}}$ ECN, Petten, The Netherlands \\ 'ASCEM, Rheden, The Netherlands \\ e LBPSIGHT, Nieuwegein, The Netherlands
}

\section{A R T I C L E I N F O}

\section{Article history:}

Received 13 August 2015

Revised 16 December 2015

Accepted 11 January 2016

Available online 5 February 2016

\section{Keywords:}

Heavy metals

Characterization

MSWI bottom ash

Leaching

Strength properties

\begin{abstract}
A B S T R A C T
Municipal solid waste incineration bottom ash was treated with specially designed dry and wet treatment processes, obtaining high quality bottom ash granulate fractions (BGF) suitable for up to $100 \%$ replacement of natural gravel in concrete. The wet treatment (using only water for separating and washing) significantly lowers the leaching of e.g. chloride and sulfate, heavy metals (antimony, molybdenum and copper) and dissolved organic carbon (DOC). Two potential bottom ash granulate fractions, both in compliance with the standard EN 12620 (aggregates for concrete), were added into earth-moist concrete mixtures. The fresh and hardened concrete physical performances (e.g. workability, strength and freezethaw) of high strength concrete mixtures were maintained or improved compared with the reference mixtures, even after replacing up to $100 \%$ of the initial natural gravel. Final element leaching of monolithic and crushed granular state BGF containing concretes, showed no differences with the gravel references. Leaching of all mixtures did not exceed the limit values set by the Dutch Soil Quality Degree. In addition, multiple-life-phase emission ( $\mathrm{pH}$ static test) for the critical elements of input bottom ash, bottom ash granulate (BGF) and crushed BGF containing concrete were assessed. Simulation pH lowering or potential carbonation processes indicated that metal (antimony, barium, chrome and copper) and sulfate element leaching behavior are mainly $\mathrm{pH}$ dominated and controlled, although differ in mechanism and related mineral abundance.
\end{abstract}

(c) 2016 Elsevier Ltd. All rights reserved.

\section{Introduction}

One of the sustainability strategies of the European Union (EU) is developing a circular economy. Potential waste and secondary materials are promoted to be re-used or recycled and subsequently applied within comparable or new processes and or applications. Hence, initial waste materials are regarded as potential new resources. This approach will ultimately lower the amount of necessary primary materials and potentially reduce the amount of materials that go into landfills. In relation to this strategy, the EU Construction Products Regulation (CPR 305/2011/EU) has come into force. This EU regulation attempts to obtain more knowledge and junction, creating a generic and level playing field between EU

\footnotetext{
* Corresponding author at: Eindhoven University of Technology, Department of the Built Environment, Eindhoven, The Netherlands and ECN, Petten, The Netherlands.

E-mail addresses: arno.keulen@vangansewinkel.com (A. Keulen), vanzomeren @ecn.nl (A. van Zomeren).
}

member states in regard to the re-use application of waste and or secondary materials (related to environmental quality) within processes.

The Netherlands is already facilitating the re-use of many types of secondary materials within construction works by a clear and workable regulation regarding the application of building materials ("(SQD) Soil Quality Degree," 2015). In addition, specific actions are initiated by the government to stimulate re-use in a sustainable way. One example is the re-use of Municipal Solid Waste Incinerator (MSWI) bottom ash, were the Dutch industry has signed a 'green-deal' with the central government to improve (towards the year 2020) the physical and environmental quality of the treated ashes. Initiating a more environmental, economically efficient and sustainable bottom ash use in constructions e.g. open granular applications for road base layers and/or secondary aggregate in asphalt and cement concrete applications.

A general, conventionally dry treated MSWI bottom ash is mainly composed non-combustible materials e.g. slag, stone, glass, 
ceramic, sand and metallic metals. Where especially metal recovery is of high economical value regarding the extraction of valuable scarce resources e.g. copper, lead, messing, zinc, aluminum and iron (Allegrini et al., 2014). The final mineral ash composition primarily consists of silicon, calcium, iron and aluminum containing structures e.g. quartz, calcite, hematite and ettringite (Chang and Wey, 2006; Chimenos et al., 1999; Funari et al., 2014; Kuo et al., 2013; Tang et al., 2015). The mineral compositions can vary time-to-time between the incinerators in relation to solid waste input and incineration conditions. Additionally, these conditions also effect the abundance and moderate concentrations of heavy metals and salts that are within the ashes (Funari et al., 2014; Margallo et al., 2015).

Treated mineral bottom ashes are to some extent comparable to the most widely used raw concrete aggregates and are therefore possibly useful as mineral additions in various construction material applications (Abbà et al., 2014; Bertolini et al., 2004; Cioffi et al., 2011; Florea, 2014; Forteza et al., 2004; Hassan and Khalid, 2010; Kuo et al., 2013; Pera et al., 1997; Syahrul et al., 2010; Toraldo et al., 2013). As such, a well-designed bottom ash granulate could potentially play an important role in the sustainable progress within Portland cement mixtures, as an aggregate alternative for primary sand and gravel. Additionally, this relative new ash application could stimulate reuse of the relatively fast growing (millions of tons) bottom ash quantities produced world-wide and that are currently and mainly stored in landfill sites (Oehmig et al., 2015).

To the authors knowledge, only a few available recent studies deal with mechanically treated MSWI bottom ash fractions in concrete, where currently no significant and satisfying results have been obtained. Research does show that, overall improved ashcontaining concrete performance is obtained with wet treated ashes in comparison with only dry treated (Rubner et al., 2008; Sorlini et al., 2011; Zhang and Zhao, 2014). Where Kuo et al. (2015) and Yang et al. (2012) attribute the difference to the finding that the liquid phase extracts and reduces a large part of the available and potentially disturbing salts, heavy metals and fine particles, present within the ashes. To summarize literature on bottom ash containing concretes compared with the Portland reference systems the following main drawbacks have been observed:

- Strong and substantial decline of fresh concrete workability (Yu et al., 2014; Zhang and Zhao, 2014).

- Severe matrix expansion and cracking by hydrogen gas production (Müller and Rübner, 2006; Yu et al., 2014).

- Cement hydration retardation by abundant disturbing substances (van Eijk, 2001).

- Severe increase of matrix porosity and permeability due to gas bubble formation (Müller and Rübner, 2006; Rubner et al., 2008; Yu et al., 2014)

- Moderate to high loss of mechanical strength (Rubner et al., 2008; Sorlini et al., 2011; Yu et al., 2014; Zhang and Zhao, 2014).

Despite these drawbacks, the mentioned studies also report multiple ash related upsides e.g., relatively good particle distribution for concrete application, equal to slightly lower material density compared to concrete aggregate (Sorlini et al., 2011), moderate to high ash particle abrasion properties, pozzolanic reaction of bottom ash particles (Zhang and Zhao, 2014) and very low economical material costs when applied as granulate.

Knowing both disadvantages and advantages, the authors elaborated a new and promising approach; applying a specially developed dry and wet treatment on the ash before being utilized in earth-moist concrete mixtures. This treatment approach and related concrete design (which will be performed on large scale and real life production pilots) has never been considered.
Until now, all published work focuses on laboratory-scale production by applying relatively wet (high consistency) concrete mixture designs (liquid/binder ratios of $\geqslant 0.4-0.6$ ) instead of dry (low to zero consistency) earth-moist designs. Interestingly, research on the earth-moist concrete production and related products are rarely published (Hüsken and Brouwers, 2008), due to difficulties to produce and simulate this production process at the laboratory scale. In practice, the production requires an extremely high pressure compaction in combination with an ideal particle packing and mixture consistency.

When applying the treated ash, the related earth-moist concrete material properties could trigger an optimized result and consequently ash usage can then be favored. Identifying the potential synergy of this approach: firstly, earth-moist concrete has no slump or measureable workability and consistency is mainly determined by the compaction rate in combination with visual inspection. Hence, workability loss initiated by the ash at its higher water demand is not of influence on the fresh concrete performance. Secondly, the relatively high porosity of earthmoist concrete is able it to capture potential hydrogen gas production from the bottom ash, preventing matrix expansion and related crack formation. Thirdly, the dry and wet ash treatment reduces the amount of disturbing substances within the bottom ash, therefore accordingly the potential negative interferences on the cement hydration can be minimized or neglected. Therefore, the following most important parameters (substances) in bottom ash treatment which influence the concrete performances that need to be controlled to obtain valuable bottom ash granulate fractions (BGF) are:

- Recovery of as much of the non-ferrous (aluminum and zinc) and ferrous metallic metals as possible that cause potential concrete expansion, cracking and pop-out problems due to hydrogen formation (Florea, 2014; Rubner et al., 2008).

- Extraction of the majority of fine and coarse unburned organic particles and their released organic structures that potentially disturb cement hydration processes (van Eijk, 2001).

- Reduce the total percentage of very-fine, mainly organic micrometer particles. These particles could interfere with the needed particle packing approach, increase water demand in the mixture, lower fresh concrete workability and retard cement hydration.

- Optimize bottom ash particle-size distribution to obtain an appropriate mineral granulate replacement for natural gravel.

- Reduce the amount of potential leachable salts, heavy metal and organic structures that influence the cement hydration or can leach into soil and groundwater systems (Cornelis et al., 2008; Dijkstra et al., 2006b; Meima and Comans, 1999, 1998; Shim et al., 2003).

Given these characteristics, this research focusses on treatment optimization of raw bottom ash where (1) all of its initial disturbing substances are selectively removed and (2) the (BGF) material is tuned to an ideal particle-size distribution. Furthermore, bottom ash granulates are first produced in a pilot experiment which combines specially designed dry and wet treatment processes. In a second pilot production, pre-fabricated earth-moist concrete elements are produced by replacing various mass percentages $(0-100 \%)$ of the natural gravel by the BGF.

The overall aims of the present work are:

- Investigate the suitability of the designed bottom ash treatment processes.

- Characterize the initial BGF material properties and their performance within open granular and concrete application. 
- Place emphasis on the leaching emissions and mechanisms in the first, second and multiple-use phases of the concrete products containing BGF as gravel replacement.

The novelty of this work is primarily the comprehensive approach to develop earth-moist concrete containing treated bottom ash. Different physical and chemical parameters important for concrete development are combined to obtain a novel bottom ash treatment process for substituting sand/gravel in concrete.

\section{Materials and methods}

\subsection{Treatment process for MSWI bottom ash}

Physical and chemical characterization of fresh MSWI bottom ash is of great importance, in producing qualitative useful concrete granulates (Florea, 2014; Rubner et al., 2008; Tang et al., 2015). Therefore, raw, untreated ash requires upgrading treatments due to its relatively heterogenic and chemically instable properties. One method, for example, is extracting all the non-mineral disturbances e.g. unburned and metallic materials. In this study, a sequence of treatment steps is performed to obtain useful granulates. Within this pilot production, up to one thousand tons of granulate was produced from MSWI bottom ash from a Dutch municipal solid waste incinerator located in Duiven. The ash was treated stepwise with dry and wet separation processes (explained below in the steps 1 to 4 ), producing optimal bottom ash granulate fractions (BGF) which were further characterized and tested as granulate in earth moist concrete. The performed BGF production process is a combination of current common practice (Biganzoli et al., 2013; Hu et al., 2008; Rem et al., 2004) and new developed dry and wet mechanical separation techniques composed of four separate treatment steps (described below). An overview of the processes and the different bottom ash fractions is shown in Fig. 1. Note that the total material input of $43 \%(\mathrm{M},-)$ within the wet treatment process increased to a $49 \%$ output. This effect is caused by water washing and saturation of the relatively porous BGF and the generated sludge fraction, which has a $50 \%$ water content.

\section{Step 1. Weathering of fresh MSWI bottom ash}

Freshly produced and quenched MSWI bottom ash was stored outside and naturally weathered for $\geqslant 3$ months. During this period, the ash slowly dries and neutralizes towards a more physically and chemically stable material (Chimenos et al., 2003; Meima and Comans, 1999; Saffarzadeh et al., 2011). This step further enhances the decrease of leaching potential of inorganic elements such as heavy metals (Aberg et al., 2006; Comans et al., 2000; Dijkstra et al., 2006b; Piantone et al., 2004). Additionally, during this time period and related high $\mathrm{pH} \geqslant 11$, significant oxidation of metallic ferrous and non-ferrous metals occurs.

\section{Step 2. Dry separation MSWI bottom ash and metal recovery}

Weathered bottom ash was first mechanically crushed and particles ( $<400 \mathrm{~mm}$ ) of mainly 'unburned' and metallic materials were extracted using a screener and powerful overhead magnet. The generated mineral fraction (BMF) was further dry separated, in the same screener, into two fractions, BMF $0-12 \mathrm{~mm}$ and $12-31.5 \mathrm{~mm}$. Fraction $0-12 \mathrm{~mm}$ was additionally separated into two fractions, BMF $0-2 / 3 \mathrm{~mm}$ (which was not further treated) and BMF 2-12 mm. Both fractions 2-12 $\mathrm{mm}$ and $12-31.5 \mathrm{~mm}$ were further processed using magnets, eddy current systems and fluff extraction apparatus to extract the maximum amount of unburned and metallic materials e.g. ferrous, non-ferrous and stainless steel (Allegrini et al., 2014). Finally, both fractions were mixed together resulting a in a BMF $2 / 3-31.5 \mathrm{~mm}$ bottom ash fraction.

\section{Step 3. Wet separation and washing treatment}

The BMF 2/3-31.5 mm was the input for the wet separation process. For this treatment, a specially designed mobile water separating-cleaning plant was built. It is a water consuming process with a liquid to solid ratio (L/S) of approximately $1: 2$ (contact-time $\pm 10 \mathrm{~min}$ ). By washing and scrubbing potential initial material disturbances e.g. very fine particles and mobile organic and inorganic leachable contaminants (organic acids, heavy metals and salts) were removed. This method was applied earlier by several other authors (Aguiar et al., 2009; Lin et al., 2011; Sorlini et al., 2011; Yang et al., 2012). The pollutants were mainly concentrated in the sludge fraction, resulting in a coarser residue with an overall

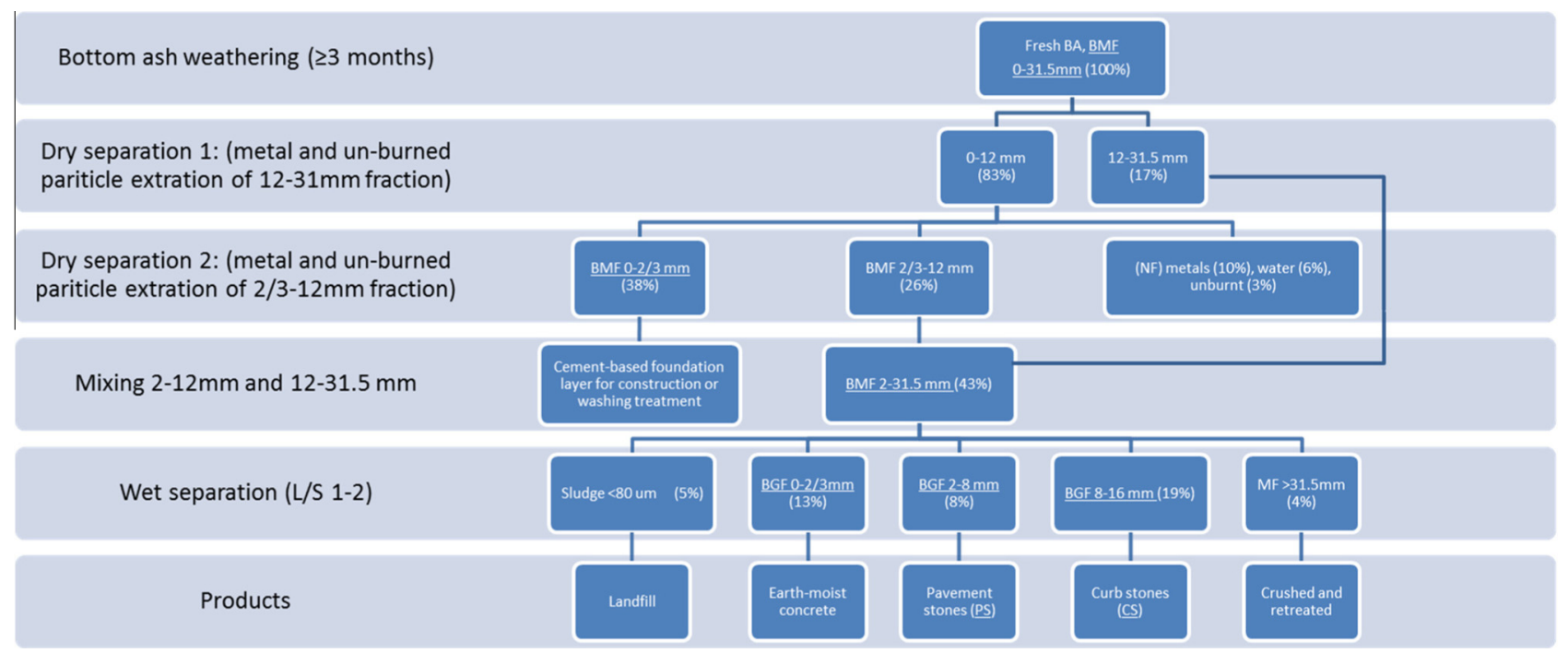

Fig. 1. Mass balance of bottom ash granulate production and treatment process. 
better environmental quality. Fig. 1 shows that five different fractions were produced: sludge $<80 \mu \mathrm{m}$, three fractions of BGF 0-4 mm, 2-8 mm, and 8-16 mm, and an oversize BMF >31.5 mm.

\section{Step 4. Final granulate treatment for concrete granulate}

Finally, both coarse fractions (BGF 2-8 mm and 8-16 mm) were additionally treated before being used in Portland cement (alkali based) concretes. Due to washing, the bottom ash was further crushed or broken to release and additional fraction of metallic non-ferrous and ferrous particles that were initially covered by ash agglomerates. These metals needed to be extracted from the material to obtain a higher metal recovery and reduce their potentially damaging effect on the concrete. Metallic metals (e.g. Al and $\mathrm{Zn}$ ) potentially initiate hydrogen gas production that can subsequently lead to expansion problems with fresh and hardened concrete and interfere with the cement hydration reaction (Müller and Rübner, 2006). Therefore, both BGF fractions were treated with magnetic separator systems to further reduce the metallic metal contents.

\subsection{Materials}

The pavement stones were produced with a blended Portland cement, a CEM III and the curbstones with a blended CEM II; both in combination with a very small addition of plasticizer (fatty acid type organic molecule). Furthermore, groundwater, natural river sand $0-4 \mathrm{~mm}$, and rounded gravel fractions of $2-8 \mathrm{~mm}$ and $8-$ $16 \mathrm{~mm}$ were used. Within the mixture design, natural aggregate replacement was done by addition of the two bottom ash granulate fraction (BGF), a $2-8 \mathrm{~mm}$ and $8-16 \mathrm{~mm}$, picture of fraction is shown in Fig. 2.

\subsection{Concrete mixture design and production}

Concrete mixtures with the addition of two types of BGF 2-8 mm and $8-16 \mathrm{~mm}$ were tested. Replacement levels of both the original natural gravel types for BGF were $0 \%, 40 \%, 70 \%$ and $100 \%$ by mass of volume. All recipes are described in Table 1 . Two element products were produced and tested; curbstones (CS) with dimensions of $1000 * 200 * 100 \mathrm{~mm}$ (length $*$ height $*$ width) and pavement stones (PS) with dimensions of $210 * 80 * 70 \mathrm{~mm}$, shown in Fig. 3 .

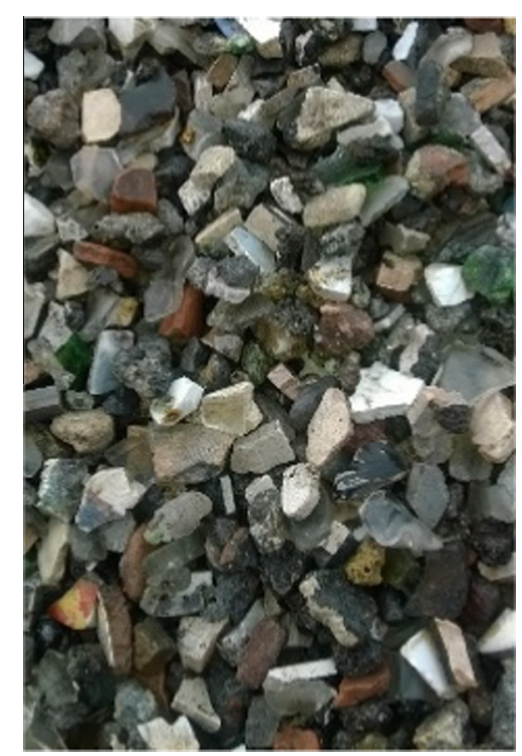

Fig. 2. Bottom ash granulate fraction $8-16 \mathrm{~mm}$.
Both elements were constructed out of two layers of concrete, a specific high performance top layer which constitutes around $10 \%$ and a bottom layer which constitutes around $90 \%$ of the total construction. BGF was added as gravel replacement in the bottom layer concrete, within the top layer BGF is at the moment not applicable as this is not in compliance to the current Dutch standards. Within the analyses, strength tests were performed on the total layer construction and all other tests were specifically performed on the BGF containing bottom layer. The numbers behind the material abbreviations (0-100\%) in Table 1 address the total amount of natural granulate replacement by BGF, within the tested concrete mixtures. Within the reference mixture $0 \%$ of BGF was used.

Factory scale production was chosen over laboratory experiments to overcome scaling problems (difficult to obtain representative products at lab-scale), and was performed at the site of 'de Hamer' in the Netherlands. Mixing was done by a wheeler batch mixer, around $1 \mathrm{~m}^{3}$ per batch, with total batch times of $3 \mathrm{~min}$. Fresh concrete was compacted within 10 min after production. After production, the specimens were kept in a climate chamber for approximately $24 \mathrm{~h}$ at $25-30{ }^{\circ} \mathrm{C}$ with a relative humidity $>60 \%$. From the climate chamber, elements were stored outside and sealed with a plastic sheet, to reduce unwanted water evaporation. In total, several hundred pavement stones and up to one hundred curbstones were produced.

\subsection{Physical material testing}

The material properties of the used natural sand and gravels and produced BGF fractions were analyzed in accordance with NEN-EN $12620(2002+A 1: 2008 \mathrm{NL})$. Additionally, BGF fractions were tested in accordance with the Dutch product standard BRL 2507 ("BRL 2507 AEC granulaat als toeslagmateriaal voor beton," 2013) which was specifically developed as a supplement guideline for use of bottom ash fractions within Portland cement and or blended cement concrete mixtures. The final concrete performance was measured for multiple material parameters, in accordance with their product standards. For strength measurements, in accordance with the standard, specimens were first water soaked for $24 \mathrm{~h}$. Total water saturation reduces possible internal stresses which could lead to unwanted deviations. Strengths were measured in accordance to the standard at 7 and 35 days. Flexural strength for curbstones ( 3 measurements per data point) was measured in accordance with the BRL 2314 (2005, class 2, mark T). Tensile strength for pavement stones ( 8 measurements per data point) were measured in accordance with BRL 2312 (2005). In addition, pavement stones were tested on freeze/thaw deicing salt resistance ( 3 measurements per data point) in accordance with NENEN 1338:2003 (E) annex D. As a preparation for the freeze/thaw measurements, stones were vertically cut in the middle (obtaining a smooth and representative surface) to test only and specifically the bottom BGF containing surface layer. All tested concrete specimens were randomly taken from the production.

\subsection{Chemical material testing}

For the leaching analysis all granular and/or monolithic samples were taken from both the granulate and/or concrete materials. Granular samples were crushed to $<4 \mathrm{~mm}$ before testing, in accordance with the appropriate test method. In the case of hardened concrete, $\varnothing 100 \mathrm{~mm}$ cylinders were drilled and crushed before granular material was tested. All monolithic samples were drilled out of the concrete elements, sample size: cylindrical $\varnothing 100 \mathrm{~mm}$ with $100 \mathrm{~mm}$ in height. The testing of granular materials was performed with the compliance percolation test in accordance with NEN 7383 (2004 NL). In this test, the leaching is measured as a function of the $\mathrm{L} / \mathrm{S}$ ratio by percolation of the bottom ash. The 
Table 1

Mixture design of earth-most concrete pavement- and curb stones.

\begin{tabular}{|c|c|c|c|c|c|c|c|c|c|c|}
\hline Mixture & CEM & Sand 0-4 (\%) & Gravel 2-8 (\%) & Gravel 8-16 (\%) & BGF $2-8(\%)$ & BGF 8-16 (\%) & Water & Plast & Cal. density & $\mathrm{W} / \mathrm{C}$ ratio \\
\hline PS-0 $\%$ & 288 & 51 & 49 & & 0 & & 104 & 0.52 & 2374 & 0.36 \\
\hline PS-40\% & 288 & 51 & 29 & & 20 & & 104 & 0.52 & 2331 & 0.36 \\
\hline PS-70\% & 288 & 51 & 14 & & 35 & & 104 & 0.52 & 2307 & 0.36 \\
\hline PS-100\% & 288 & 50 & 0 & & 50 & & 104 & 0.52 & 2283 & 0.36 \\
\hline CS-0\% & 309 & 50 & 33 & 17 & & 0 & 111 & 0.43 & 2354 & 0.36 \\
\hline CS-40\% & 309 & 51 & 20 & 9 & & 20 & 111 & 0.43 & 2331 & 0.36 \\
\hline CS-70\% & 309 & 51 & 11 & 3 & & 35 & 111 & 0.43 & 2314 & 0.36 \\
\hline CS-100\% & 309 & 49 & 1 & 0 & & 50 & 111 & 0.43 & 2295 & 0.36 \\
\hline
\end{tabular}

All values in $\mathrm{kg} / \mathrm{m}^{3}$.

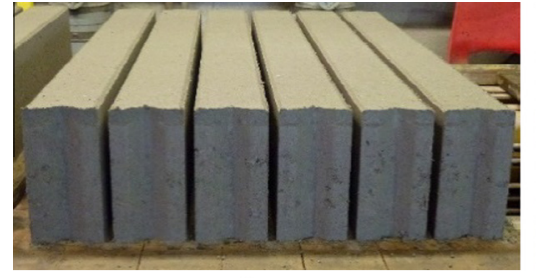

a

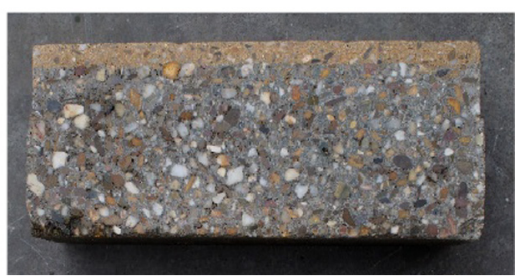

b

Fig. 3. Curb stone with BGF $8-16 \mathrm{~mm}$ (a) and pavement stone with BGF 2-8 mm (b).

cumulative emission at $\mathrm{L} / \mathrm{S}=10 \mathrm{~L} / \mathrm{kg}$ is measured in one cumulative eluate fraction.

Monolithic materials were tested using the tank leaching test in accordance with NEN 7375 (2004 NL). All tested concrete 'monolithic and granular samples' were around 35 days old when the tests were performed. Chemical analysis of leachates from leaching tests was performed by inductively coupled plasma atomic emission spectroscopy (ICP-AES). Chloride ( $\mathrm{Cl}$ ), bromide $(\mathrm{Br})$ and sulfate $\left(\mathrm{SO}_{4}\right)$ were analyzed using ion chromatography (IC). Fluoride was analyzed by flow injection analyses with spectroscopic detection.

Batch pH-static leaching experiments were carried out according to EN 14997 on subsamples that were each equilibrated for $48 \mathrm{~h}$ at a predetermined $\mathrm{pH}$ value between $\mathrm{pH} 2$ and 12 . The samples BMF 0-31.5 mm, BGF 2-16 mm (mixture of BGF 2-8 mm and $8-16 \mathrm{~mm}$ ) and concrete sample PS- $100 \%$ were used for the $\mathrm{pH}$ dependence leaching test. Within this method $15 \mathrm{~g}$ of dry bottom ash was suspended in $150 \mathrm{~g}$ nanopure demineralized water (L/S ratio of $10 \mathrm{~L} / \mathrm{kg}$ ) in acid-cleaned $300 \mathrm{~mL}$ PTFE vessels, under continuous stirring at $20^{\circ} \mathrm{C}$ in contact with the atmosphere. The $\mathrm{pH}$ of the different suspensions was controlled using solutions of $1 \mathrm{M} \mathrm{HNO}_{3}$ and $\mathrm{NaOH}$ (analytical grade) and a computerized $\mathrm{pH}$-stat system. After the equilibration period, the suspensions were filtered through $0.45 \mu \mathrm{m}$ membrane filters. The filtrates were acidified with concentrated $\mathrm{HNO}_{3}$ (Suprapur ${ }^{\circledR}$ ) and analyzed by ICP-AES to obtain solution concentrations of a wide spectrum of major and minor elements. It was assumed that total Sulfur $(\mathrm{S})$ as measured by ICP-AES equated to $\mathrm{SO}_{4}$ (factor 3 to convert $\mathrm{S}$ to $\mathrm{SO}_{4}$ ).

\section{Results and discussion}

In this paragraph, two possible granular application routes for the produced BGF fractions are investigated. First, produced BGF was tested for potential application as a granular construction product for open application in road bases or embankments. Second, BGF was tested as natural gravel replacement within earth-moist concrete.

\subsection{Bottom ash treatment and application feasibility as a granular construction material}

The produced raw, untreated bottom ash (BMF) was subjected to several dry and wet separation steps to upgrade the environ- mental quality and to produce fractions with desirable physical properties, see Section 2.1. To assess the open application re-use possibilities, the bottom ash input material, which was combined with several fractions at different steps in the process and the final granulates, leaching was tested using the percolation leaching test (NEN 7383). The results in Table 3 show a number of interesting features regarding the treatment processes. The input material (BMF 0-31.5 mm) already had a relatively low $\mathrm{pH}$ in comparison with freshly produced bottom ash. This is most likely a result of the natural weathering period of 3 months. Its $\mathrm{pH}$ decrease as a result of weathering has been reported by other authors (Arickx et al., 2010; Dijkstra et al., 2006a; Meima and Comans, 1998). The leaching of most regulated substances did already comply with the limit values ("(SQD) Soil Quality Degree," 2015) for an open application. However, the leaching of antimony (Sb), copper $(\mathrm{Cu})$, chloride $(\mathrm{Cl})$ and sulfate $\left(\mathrm{SO}_{4}\right)$ exceeded their limit values (bromide $(\mathrm{Br})$ is just below the limit value). It is known that the leaching of these elements can be close to the limit values for open application (Dijkstra et al., 2006a), emphasizing the need for quality improvement of dry treated bottom ash. The further dry separation into a fine fraction (BMF 0-2/3 mm) and a coarse fraction (BMF 2/3$31.5 \mathrm{~mm}$ ) clearly indicates that the relatively mobile substances $\mathrm{Mo}, \mathrm{Sb}, \mathrm{Br}, \mathrm{Cl}$ and $\mathrm{SO}_{4}$ are preferentially concentrated in the fine fraction. It is postulated that these elements are already dissolved mostly in the pore water of the bottom ash and are transferred to the fine fraction together with most of the water from the bottom ash. Furthermore, in the case of sulfate, release is mainly controlled by gypsum solubility (Cornelis et al., 2008; Meima and Comans, 1998). Gypsum, a sulfate source, is believed to be vulnerable to the sieving treatments due to its low mineral brittleness. It is easily crushed during sieving and becomes more concentrated in the fine BMF 0-2/3 mm fraction. As a result, the coarse BMF 2-31.5 mm shows a substantial reduction of sulfate and chloride and, to a somewhat lesser extent, bromide leaching. It is noted that the Mo leaching in the coarse fraction seems to be somewhat higher than the original input material. Which might be explained by the weak $\mathrm{pH}$ dependent adsorption of Mo by reactive iron/aluminum (Fe/Al)-(hydr)-oxide surfaces of less reactive coursersized bottom ash particles e.g. glasses and ceramics (Cornelis et al., 2008; Dijkstra et al., 2006b). The same mechanism might also explain the leaching of $\mathrm{Sb}$ between the fractions. Overall, the results of the dry separation treatment show that this technology 
positively affects the leaching of Mo, Sb, chloride and sulfate and to a lesser extent bromide. However, the produced coarse fraction (BMF 2-31.5 mm) does not comply with the criteria of open application (SQD) with respect to the leaching of $\mathrm{Cu}, \mathrm{Cl}$ and $\mathrm{SO}_{4}$. The leaching of $\mathrm{Sb}$ and Mo are close to their limit values.

The bottom ash was also wet treated with a water separation step to a cumulative $\mathrm{L} / \mathrm{S}$ ratio $1-2 \mathrm{~L} / \mathrm{kg}$. The use of water in this step also implies that bottom ash is washed during separation, to reduce its mobile constituents (Yang et al., 2012). The leaching of the three resulting bottom ash granulate fractions (BGF) were analyzed with the percolation test (Table 3 ). In general, this treatment step had a very positive effect on the reduction of leaching of the mobile elements $\mathrm{Sb}, \mathrm{Cu}, \mathrm{Mo}, \mathrm{Br}, \mathrm{Cl}$, and $\mathrm{SO}_{4}$. The dry and wet separation of bottom ash shows potential, reducing the leaching of BGF that than can comply with the SQD leaching criteria for open application; although $\mathrm{Cl}$ and $\mathrm{SO}_{4}$ leaching can sometimes still be critical. However, it is observed that the $\mathrm{Cl}$ content is strongly reduced within the $\mathrm{BGF}$ and a slight $\mathrm{Cl}$ increase in the washed BGF as a function of larger particle size is observed, shown in Table 3. This effect might be explained by the higher porosity of larger particles that can lead to higher (chloride containing) water absorption and, hence, more dissolved $\mathrm{Cl}$ in that bottom ash fraction. If necessary, a further reduction of leachable $\mathrm{Cl}$ and $\mathrm{SO}_{4}$ from the BGF fractions can be obtained by increasing the $\mathrm{L} / \mathrm{S}$ ratio and contact time during washing and/or the water refreshing rate within the process (Stegemann et al., 1995; Yang et al., 2012). An important observation is that during the wet treatment process the Sb leaching is not lowered when comparing input BMF 2$31.5 \mathrm{~mm}$ with both washed course BGF fractions. However, this effect is noticeable when comparing BMF $0-2 / 3 \mathrm{~mm}$ input with the washed $0-4 \mathrm{~mm}$ BGF fraction where $\mathrm{Sb}$ emission is reduced $>50 \%$. In addition, in a preliminary pilot washing test a lowering effect on Sb release was also noticed, where the input bottom ash fraction $0-31.5 \mathrm{~mm}$ contained about $1.0 \mathrm{mg} / \mathrm{kg} \mathrm{dm}$ (dm: dry material) and the produced granulate fractions $4-20 \mathrm{~mm}$ about $0.25-0.44 \mathrm{mg} / \mathrm{kg} \mathrm{dm}$ (reduction of about $>50 \%$ ). This effect could be attributed to availability and the washing out of a large part of the soluble state penta antimonite $\left(\mathrm{Sb}_{2} \mathrm{O}_{5}\right)$, which is likely to be present in weathered bottom ash eluate (Cornelis et al., 2012; Dijkstra et al., 2006a; Meima and Comans, 1998; Paoletti et al., 2001). Due to washing this metal species is transferred to the washing water and the produced sludge residue. However, the $\mathrm{Sb}$ release from the granular material can still be at critical limit value for open application. Considering the leaching of all regulated substances in the BMF and BGF samples (Table 3), it is concluded that the wet separation technology strongly improves the overall environmental quality of most of the initial mobile abundant elements ( $\mathrm{Sb}, \mathrm{Ba}, \mathrm{Cu}, \mathrm{Mo}, \mathrm{Cl}, \mathrm{SO}_{4}$ and $\mathrm{Br}$ ). Although in the case of the course washed fractions, $\mathrm{Sb}$ reducing is less noticeable.
Finally, the results of this study show that both dry and wet separation are favored in order to improve the initial environmental quality of the washed course-size bottom ash fractions. The leaching of $\mathrm{Cl}$ and $\mathrm{Sb}$ could remain critical to meet the SQD limit values for an open application (using an L/S ratio of 1-2). Therefore, the option to use the BGF as a gravel replacement in concrete was also assessed.

\subsection{BGF application as a gravel replacement in concrete}

Previous research showed that particles shape, distribution, material porosity and density of MSWI bottom ash aggregates differs compared with natural aggregates which, in the end could influence the final fresh and hardened physical properties of a cement based concrete product (Chimenos et al., 1999; Tang et al., 2015). The tested bottom ash granulate fractions within this study are specifically developed to overcome many of the more or less unwanted and till now known properties. To gain optimal and effective replacement properties, the particle-size distribution (PSD) of both BGF fractions (Fig. 4) were modified by adjusting the sieving mesh size within the wet treatment to resemble natural aggregates. When comparing their PSD, the recycled and natural materials do show some difference in the particle shape and to a lesser extent also in particle-size distribution, although the variation within the PSD of the BGF fractions are limited to about 5$15 \%$. The variation fits within the criteria of the NEN-EN 12620 (aggregates for concrete). This also shows that with the wet treatment process is effective with which an adjustable BGF particle distribution can be obtained. Furthermore, the BGF is more rectangularly shaped than the natural round aggregate which mainly originates from the slag, glass and ceramic particles. BGF shows a higher material porosity and related water absorption, mainly caused by the porous slag particles.

The analyzed material properties of the BGF relevant for the requirements to produce concrete are described in Table 2. Parameters such as Loss on ignition (LOI 500), Alkali equivalent, Metallic Al $(+\mathrm{Zn})$ and the sulfur trioxide $\left(\mathrm{SO}_{3}\right)$ content are not measured for natural gravel as these are only relevant for bottom ash fractions that are considered for use in concrete. The requirements for re-use of bottom ash in concrete and the test methods to be used are described in Dutch guidance document ("BRL 2507 AEC granulaat als toeslagmateriaal voor beton," 2013). Table 2, indicates that all tested BGF parameters meet their limits specified in NEN-EN 12620 and NEN 5905. Therefore, it is concluded that the BGF properties seem to be compatible with the requirements to replace natural gravel with BGF in concrete. Another important parameter that determines the application of BGF as aggregate replacement in concrete is the emission of contaminants from the concrete to soil and ground water. Hence, the tank leaching test was performed on

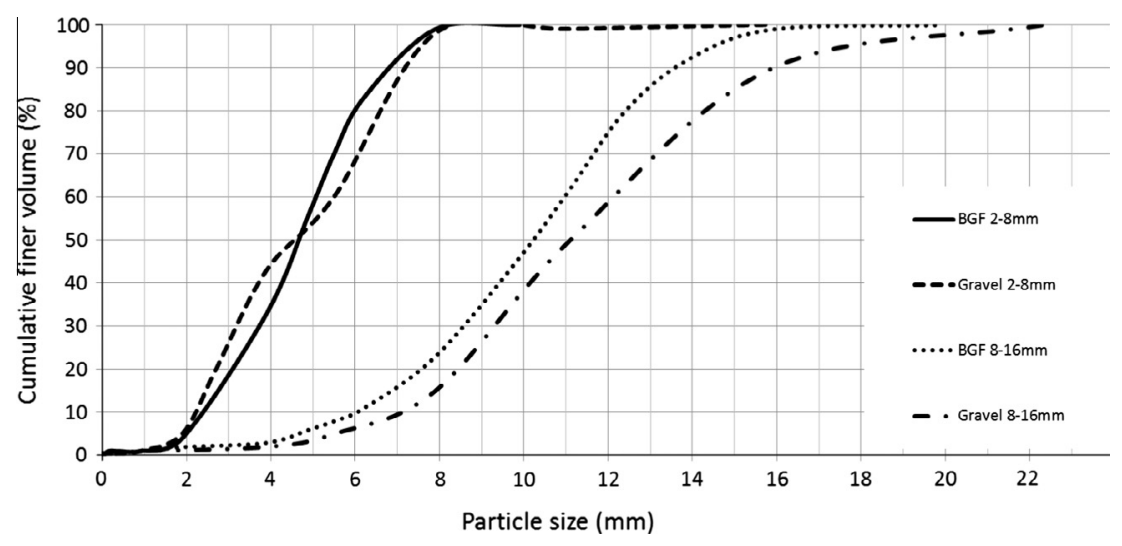

Fig. 4. Particle-size distribution of natural gravel and BGF fractions of both at $2-8 \mathrm{~mm}$ and at $8-16 \mathrm{~mm}$ size fractions. 
Table 2

Material properties of raw materials for concrete production.

\begin{tabular}{|c|c|c|c|c|c|c|c|c|}
\hline Parameter & BGF 2-8 & BGF 8-16 & Sand $0-4$ & Gravel 2-8 & Gravel 8-16 & CEM II & CEM III & Limit $^{a}$ \\
\hline LOI 500 (\% mass) & 0.95 & 0.59 & n.m. & n.m. & n.m. & n.m. & 1.0 & $\leqslant 5.0$ \\
\hline Alkali equivalent (\% mass) & 0.14 & 0.16 & n.m. & n.m. & n.m. & 0.59 & 0.77 & $\leqslant 0.2$ \\
\hline Metallic Al (\% mass) & 0.47 & 0.29 & n.m. & n.m. & n.m. & n.m. & n.m. & \\
\hline Metallic $\mathrm{Al}+\mathrm{Zn}$ (\% mass) & 0.73 & 0.80 & n.m. & n.m. & n.m. & n.m. & n.m. & $\leqslant 1.0$ \\
\hline $\mathrm{SO}_{3}$ (\% mass) & 0.15 & $<0.03$ & n.m. & n.m. & n.m. & n.m. & n.m. & $\leqslant 0.8$ \\
\hline Anhydrite (\% mass) & n.m. & n.m. & n.m. & n.m. & n.m. & 2.8 & 3.3 & \\
\hline Chloride content (\% mass) & $\leqslant 0.03$ & $\leqslant 0.03$ & $\leqslant 0.003$ & $\leqslant 0.003$ & $\leqslant 0.003$ & 0.04 & 0.06 & \\
\hline Los Angeles (LA) coefficient & 33 & 31 & $>35$ & $>35$ & $>35$ & n.m. & n.m. & \\
\hline Density $P_{r \mathrm{~d}}\left(\mathrm{~kg} / \mathrm{m}^{3}\right)$ & $2400^{\mathrm{b}}$ & $2250^{\mathrm{b}}$ & 2640 & 2570 & 2570 & 3000 & 3020 & $\geqslant 2000$ \\
\hline Water absorption $24 \mathrm{~h}$ (\% mass) & 6.9 & 6.8 & 0.2 & 1.3 & 1.3 & n.m. & n.m. & \\
\hline
\end{tabular}

n.m.: not measured.

a Limit values in accordance to NEN-EN 12620/NEN 5905.

b $\pm 100 \mathrm{~kg} / \mathrm{m}^{3}$.

Table 3

Total element emission measured with percolation test (NEN 7383) of granular state bottom ash fractions from different treatment processes.

\begin{tabular}{|c|c|c|c|c|c|c|c|}
\hline Parameter & BMF 0-31.5 & BMF $0-2 / 3$ & BMF 2-31.5 & BGF 0-4 & BGF 2-8 & BGF 8-16 & Limit granular material \\
\hline$n$ & 3 & 2 & 1 & 1 & 1 & 1 & \\
\hline $\mathrm{pH}$ & 8.41 & 8.14 & 9,04 & 8.46 & 8.41 & 8.45 & No limit \\
\hline $\mathrm{EC}$ & 1681 & 2495 & 730 & 956 & 696 & 654 & No limit \\
\hline Antimony & 0.55 & 0.68 & 0.25 & 0.30 & 0.30 & 0.28 & 0.32 \\
\hline Arsenic & 0.08 & $<0.10$ & 0.05 & $<0.10$ & $<0.10$ & $<0.10$ & 0.90 \\
\hline Barium & 0.39 & 0.39 & 0.50 & 0.28 & 0.20 & 0.17 & 22.00 \\
\hline Cadmium & $<0.0085$ & $<0.01$ & $<0.01$ & $<0.01$ & $<0.01$ & $<0.01$ & 0.04 \\
\hline Chromium & 0.05 & $<0.10$ & 0.05 & $<0.10$ & $<0.10$ & $<0.10$ & 0.63 \\
\hline Cobalt & 0.04 & $<0.10$ & 0.03 & $<0.10$ & $<0.10$ & $<0.10$ & 0.54 \\
\hline Copper & 1.53 & 1.45 & 1.30 & $<0.15$ & $<0.15$ & $<0.15$ & 0.90 \\
\hline Mercury & $<0.0012$ & 0.005 & 0.00 & $<0.005$ & $<0.005$ & $<0.005$ & 0.02 \\
\hline Lead & $<0.10$ & $<0.10$ & $<0.10$ & $<0.10$ & $<0.10$ & $<0.10$ & 2.30 \\
\hline Molybdenum & 0.51 & 1.20 & 0.84 & 0.32 & 0.23 & 0.20 & 1.00 \\
\hline Nickel & 0.09 & $<0.10$ & 0.05 & $<0.10$ & $<0.10$ & $<0.10$ & 0.44 \\
\hline Selenium & 0.01 & $<0.039$ & 0.01 & $<0.039$ & $<0.039$ & $<0.039$ & 0.15 \\
\hline Tin & 0.02 & $<0.10$ & 0.02 & $<0.10$ & $<0.10$ & $<0.10$ & 0.40 \\
\hline Vanadium & $<0.10$ & $<0.10$ & $<0.10$ & $<0.10$ & $<0.10$ & $<0.10$ & 1.80 \\
\hline Zinc & $<0.20$ & $<0.20$ & $<0.20$ & $<0.20$ & $<0.20$ & $<0.20$ & 4.50 \\
\hline Fluoride & 5.6 & 2.3 & 2.4 & 4.0 & 2.6 & 2.4 & 55 \\
\hline Chloride & 2725 & 4950 & 1700 & 550 & 570 & 687 & 616 \\
\hline Sulfate & 6533 & 11,000 & 3200 & 3367 & 1833 & 1393 & 2.430 \\
\hline Bromide & 18.8 & 25.0 & 14.0 & 2.8 & 3.0 & 3.5 & 20 \\
\hline
\end{tabular}

All values in $\mathrm{mg} / \mathrm{kg} \mathrm{dm}$. Bold: above limit value.

$n$ : Sample amount.

concrete curb stones (CS) samples to assess leaching using gravel replacement rates from $0-100 \%$. The results reported in Table 4 show that all BGF containing concrete mixtures comply with the limit values for monolithic construction materials. However, with an increasing replacement rate of BGF, it results in even slightly lower emissions of metals, although it is unclear whether this difference is significant. A possible explanation for this effect, is sorption and or complexation of leachable mobile 'heavy' metals on reactive $\mathrm{Fe} / \mathrm{Al}$-(hydr)-oxide and glassy surfaces within the porous slag. This would enable an additional barrier for further transport through the cementitious matrix (Cornelis et al., 2008; Piantone et al., 2004; Saffarzadeh et al., 2011; Zevenbergen et al., 1996). Finally, only the leaching of $\mathrm{Cl}$ seems to be slightly increased within the sample with $100 \%$ gravel replacement with BGF (CS-100). However, the measured $\mathrm{Cl}$ release $\left(470 \mathrm{mg} / \mathrm{m}^{2}\right)$ is still more than two orders of magnitude below the limit value $\left(110.000 \mathrm{mg} / \mathrm{m}^{2}\right)$. Overall, the results of the curb stones with BGF replacement rates between $0 \%$ and $100 \%$ have obtained an environmental quality which fulfills the requirements specified by the SQD.

\subsection{Fresh and hardened concrete properties with increasing BGF content}

During the production at total quantity of $>20$ ton, fresh earth-moist (zero slump) concrete was produced. The fresh
Table 4

Total element emission measured with the diffusion test (NEN 7375) of monolithic state curb stone concrete with increasing natural gravel replacement with BGF 8$16 \mathrm{~mm}$.

\begin{tabular}{lllll}
\hline Parameter & CS-0\% & CS-40\% & CS-100\% & Limit monolithic material \\
\hline pH start & 11.6 & 11.6 & 9.8 & No limit \\
pH end & 11.9 & 11.9 & 11.5 & No limit \\
Antimony & 0.4 & 0.4 & 0.4 & 8.7 \\
Arsenic & 4.0 & 4.0 & 2.2 & 260 \\
Barium & 19.0 & 20.0 & 3.3 & 1.500 \\
Cadmium & 0.1 & 0.1 & 0.04 & 3.8 \\
Chromium & 4.0 & 4.0 & 2.2 & 120 \\
Cobalt & 2.4 & 2.4 & 1.3 & 60 \\
Copper & 4.0 & 4.0 & 2.2 & 98 \\
Mercury & 0.02 & 0.02 & 0.02 & 1.4 \\
Lead & 8.0 & 8.0 & 4.4 & 400 \\
Molybdenum & 0.8 & 0.8 & 0.6 & 144 \\
Nickel & 4.0 & 4.0 & 2.2 & 81 \\
Selenium & 0.6 & 0.6 & 0.3 & 4.8 \\
Tin & 1.6 & 1.6 & 0.9 & 50 \\
Vanadium & 8.0 & 8.0 & 4.8 & 320 \\
Zinc & 16.0 & 16.0 & 8.7 & 800 \\
Fluoride & 128 & 96 & 49 & 2.500 \\
Chloride & 88 & 80 & 470 & 110.000 \\
Sulfate & 960 & 960 & 1200 & 165.000 \\
Bromide & 2 & 2 & 5 & 670 \\
\hline All values in & 2 & & &
\end{tabular}

All values in $\mathrm{mg} / \mathrm{m}^{2} / 64$ days. 
material properties did not vary significantly as a result of the BGF (0-100\%) replacement. The consistencies and compaction rates of the mixtures, also known as 'green' strength, were all approximately equal (visually and manually judged). The additional mixture workability, also known as the open time or setting time, was likewise not influenced by increasing BGF quantities, although it is known that an increase of salts such as chloride and sulfate can accelerate or retard cement hydration (Cheung et al., 2011). The BGF fractions have up to 5 times higher water absorption rates $( \pm 7 \%)$ compared to natural gravel $( \pm 1.3 \%)$. This high absorption is mainly related to the porous slag content and could affect the workability properties when it is not fully saturated during usage. However, this high BGF water content may also act as an 'internal aquifer', which may further enhance internal cement hydration, resulting in a higher strength developed and matrix densification. This can be advantageous in earth-moist concrete mixtures, where a relative low water to binder (W/B) ratio is usually used, which would result in less efficient cement hydration by too low water contents.

\subsection{Concrete strength of pavement stones with BGF 2-8 mm content}

The pavement stones were constructed out of two concrete layers, a thin top layer $(0.5-1.0 \mathrm{~cm})$ and thick $(7.0-7.5 \mathrm{~cm})$ bottom layer. Only the bottom layer comprises of various replacement levels of BGF $2-8 \mathrm{~mm}$. The whole stone specimen was tested on tensile strength development, from $0 \%$ up to $100 \%$ gravel replacement, of which the data is shown in Fig. 5. The 7 days strengths were stable at around $3.7 \mathrm{~N} / \mathrm{mm}^{2}$. At 35 days, strength results slightly increase at higher BGF replacement levels (from $4.5 \mathrm{~N} /$ $\mathrm{mm}^{2}$ with $0 \%$ BGF up to $5.1 \mathrm{~N} / \mathrm{mm}^{2}$ with $100 \%$ BGF). However, this increase of $12 \%$ is deemed not to be significant with respect to the standard deviations of the analyses. Finally, all mixtures comply with the strength limit of $3.5 \mathrm{~N} / \mathrm{mm}^{2}$ at 35 days related to the standard. The authors propose several mechanisms to explain the observed increase in strength:

- The improvement of the attachment of inner particles due to the introduction of rougher and more rectangularly shaped BGF. This enables a better mineral resilience between the aggregates and the cement binder in comparison with the round and more smoothly shaped gravel.

- The production of earth-moist concrete and its related low L/B ratio, is known as insufficient in generating an effective cement hydration. The mineral BGF matrix with its relatively high porosity and related high water absorption $( \pm 7 \%)$ could act as an inner aquifer which slowly releases water over time, resulting in more effective cement hydration and related strength growth.

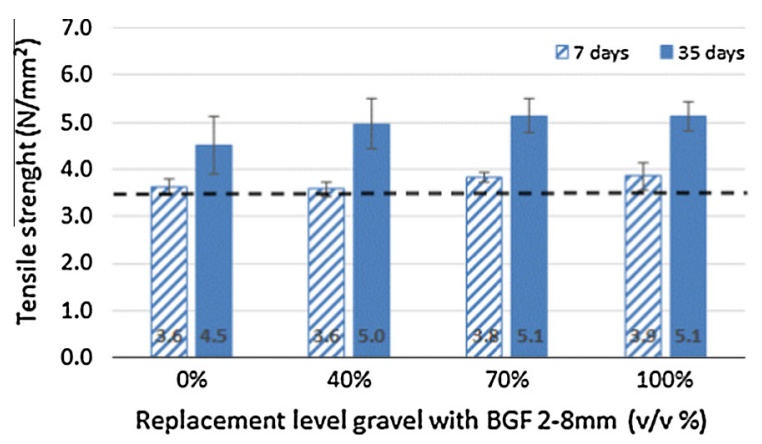

Fig. 5. Tensile strength of pavement stones with increasing replacement levels (0$100 \%$ ) of BGF $2-8 \mathrm{~mm}$ for natural gravel $2-8 \mathrm{~mm}$. Strength limit value at 35 days is $3.5 \mathrm{~N} / \mathrm{mm} 2$.
- The smaller sized BGF contains a relatively high percentage of potential pozzolanic reacting bottom ash slag compared with the larger BGF fraction. This may act as reactive hydraulic aggregate to gain additional matrix densification and reduced porosity (Zhang and Zhao, 2014), resulting in higher strength development at 35 days and beyond (Piantone et al., 2004; Zevenbergen et al., 1996)

To obtain a better understanding of the mechanisms behind these results, further research into the binding mechanism between the cement and the GBF in comparison with the gravel is necessary.

\subsection{Concrete strength of curb stones with BGF 8-16 mm content}

The curb stone elements were similar to the pavement stones, produced out of two layers of concrete and BGF 8-16 mm was added only in the bottom layer. Their observed overall flexural strength development is somewhat different compared to the tensile strength of the pavement stones. At 7 days, a stable flexural strength $\left(6.0 \mathrm{~N} / \mathrm{mm}^{2}\right)$ is gained at $0-40 \%$ of BGF contents. However, strengths slightly decreased to $5.2 \mathrm{~N} / \mathrm{mm}^{2}$ at $70-100 \%$ of BGF contents, of which the data is shown in Fig. 6. This overall effect is also reproduced at the 35 days strength development. At 0-40\% BGF addition, the 35 days strength reached an average of $6.6 \mathrm{~N} / \mathrm{mm}^{2}$ and decreased to an average of $5.8 \mathrm{~N} / \mathrm{mm}^{2}$ at higher than $40 \%$ BGF contents. This $5.8 \mathrm{~N} / \mathrm{mm}^{2}$ strength means about $12 \%$ loss compared to the reference, although it is not significant to the level of BGF added. In summary, a stable and one time strength loss at both 7 and 35 days was observed when more than $40 \%$ of BGF was added. However, all curb stone mixtures comply with the 35 days strengths limit of $5.0 \mathrm{~N} / \mathrm{mm}^{2}$, in accordance with the standard. The authors propose the following mechanisms for the observed strength decrease:

- Strength is influenced by the decline of particle's hardness/ abrasion (also known as Los Angeles coefficient). The hardness of the BGF $8-16 \mathrm{~mm}$ (value $\geqslant 31$ ) is slightly lower compared to the BGF $2-8 \mathrm{~mm}$ ( $\geqslant 33$ ) and both moderately lower compared to the natural aggregates (value $\geqslant 35$ ), which results in a potential weaker matrix.

- The smoothness of particles can be of influence, as the BGF 8$16 \mathrm{~mm}$ contains a relatively high content of large sized ceramics and glass particles compared to the BGF 2-8 $\mathrm{mm}$. The poor shape of these coarse glass and ceramic aggregates causes a decrease in adhesive strength between the BGF aggregate and the cement paste, resulting in a decreased flexural strength (Jani and Hogland, 2014). Overall, when using only the BGF 2$8 \mathrm{~mm}$ instead of $8-16 \mathrm{~mm}$ fractions, as with the pavement stones, the observed strength loss may be further minimized.

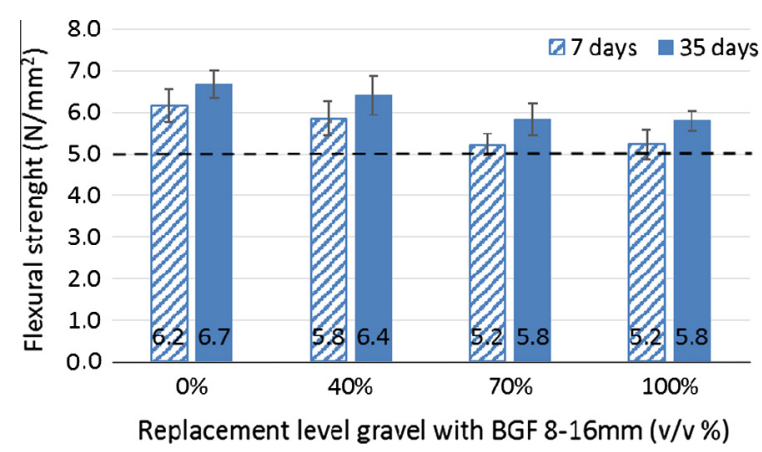

Fig. 6. Flexural strength of curb stones with increasing replacement levels $(0-100 \%)$ of BGF $8-16 \mathrm{~mm}$ for natural gravel $8-16 \mathrm{~mm}$. Strength limit value at 35 days is $5.0 \mathrm{~N} / \mathrm{mm} 2$. 
- The course BGF, which has a lower specific surface area, contains much less potential pozzolanic slag particles compared with the fine BGF, which results in suppressed later age (35 days) strength development.

In consistency with the results of pavement stone strengths, further research on the aggregate/cement binding mechanism is necessary.

\subsection{Freeze-thaw deicing salt resistance of BGF containing pavement stones}

An average Northern European climate requires specific freezethaw deicing salt resistance properties of outdoor concrete elements. In this study, these measurements were performed by determining the surface mass loss $/ \mathrm{m}^{2}$ of the bottom layers of pavement stones that contain the BGF 2-8 mm. The top layers of the pavement stones were not tested, as they are composed of only primary aggregates in combination with a higher binder content. As shown in Fig. 7, the obtained mass loss results of the BGF containing concrete showed no significant increase with higher BGF contents. An average of $\pm 0.220 \mathrm{~kg} / \mathrm{m}^{2}$ is obtained with no significant differences between the $0 \%$ reference and $100 \%$ BGF replacement. All measured values are well below the prescribed limit of $1.0 \mathrm{~kg} / \mathrm{m}^{2}$. To summarize, even at higher BGF contents, and therefore higher porosity and potentially higher liquid adsorption, no performance loss was observed. This indicates that the performance of BGF related to freeze-thaw resistance is also in compliance, similarly to the natural gravels that are nowadays used as high performance top layer aggregates.

\subsection{Potential emissions of bottom ash and concrete products in multiple life phases}

\subsubsection{Second life emissions of crushed and demolished pavement stones}

Although the CPR indicates that emissions of construction products should not have an exceedingly high impact over the entire life cycle, there is currently no regulatory framework to assess this property. Therefore, additional experiments were performed indicating potential trends in material behavior in a second or multiple life phase. As a first step, it can be imagined that the BGF containing concrete ends as crushed construction and demolition product. This material can be used as recycled aggregate (second life) suitable as concrete aggregate, road base material or other granular construction applications and should be tested with a percolation leaching test according to Dutch regulations. Leaching data shown in Table 5 , is obtained from crushed concrete with $0 \%, 40 \%$ and

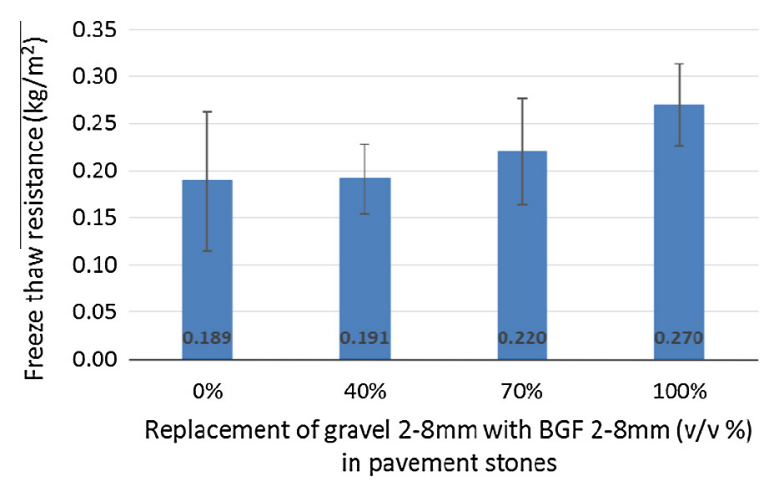

Fig. 7. Freeze-thaw resistance of pavement stones with increasing replacement levels $(0-100 \%)$ of BGF $2-8 \mathrm{~mm}$ for natural gravel $2-8 \mathrm{~mm}$. Limit value is $1 \mathrm{~kg} / \mathrm{m}^{2}$.
$100 \%$ of BGF, replacing the gravel content. The results shows that the overall leaching of all crushed pavement stones is in compliance with the limit values for an open (granular) application used within a second life. Nevertheless, there seems to be a slight increase of only salts release at higher BGF replacement levels e.g. $\mathrm{Cl}, \mathrm{SO}_{4}$ and $\mathrm{Br}$ leaching. However these emissions remained far below the limit values.

\subsubsection{Multiple life emissions of crushed and demolished pavement stones}

It is known that alkaline materials have a tendency to carbonate, take up $\mathrm{CO}_{2}$ from the atmosphere during their life time (Dijkstra et al., 2006a; Meima and Comans, 1998; Meima et al., 2002). The extent to which this process occurs and how it affects the material properties, is dependent on the material performance, application scenario and time. The potential endpoint of the Portland cement based carbonation process is the equilibrium with the mineral calcite $\left(\mathrm{CaCO}_{3}\right)$, resulting in a $\mathrm{pH}$ of about 8.5 .

To approximate and compare potential effects of $\mathrm{pH}$ neutralization of the concrete pavement stones and to study this behavior, various bottom ash materials from this study were tested with the $\mathrm{pH}$ dependent leaching test e.g. untreated bottom ash (BMF 0-31.5 mm), treated bottom ash granulate (BGF 2-16 mm) and crushed pavement stone concrete (PS-100\%). The test results (Fig. 8) indicate trends in the emission of substances considering $\mathrm{pH}$ changes over the multiple life cycles of the material. This approach has also been used several times to identify release controlling phases and can assist in the development of treatment technologies to improve the leaching behavior (Cornelis et al., 2012; Dijkstra et al., 2006b; Gougar et al., 1996; Meima and Comans, 1999; Vítková et al., 2009). The results of the pH dependence tests for $\mathrm{Ba}, \mathrm{Cu}, \mathrm{Sb}, \mathrm{SO}_{4}$ and chromium $(\mathrm{Cr})$ are presented in Fig. 8. The leaching of barium from the pavement stones, in

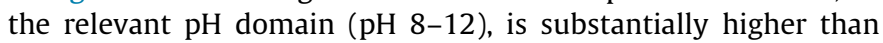
both bottom ash materials (untreated BMF and the treated BGF materials in Table 3). These observations are also consistent with the percolation test results in Table 5 , showing already a high $\mathrm{Ba}$ release from the reference concrete with $100 \%$ gravel (PS-0\%). This observation might be explained by a lower amount of carbonate in the concrete in comparison with the bottom ash. Between

Table 5

Total element emission of granular state pavement stone concrete with increasing natural gravel replacement with BGF 2-8 $\mathrm{mm}$.

\begin{tabular}{lllll}
\hline Parameter & PS-0\% & PS-40\% & PS-100\% & Limit granular material \\
\hline pH end & 12.4 & 12.2 & 12.1 & No limit \\
Antimony & 0.01 & 0.01 & 0.02 & 0.32 \\
Arsenic & $<0.05$ & $<0.05$ & $<0.05$ & 0.90 \\
Barium & 5.00 & 4.40 & 5.00 & 22.00 \\
Cadmium & $<0.001$ & $<0.001$ & $<0.001$ & 0.04 \\
Chromium & $<0.05$ & $<0.05$ & $<0.05$ & 0.63 \\
Cobalt & $<0.03$ & $<0.03$ & $<0.03$ & 0.54 \\
Copper & $<0.05$ & 0.10 & 0.20 & 0.90 \\
Mercury & $<0.0004$ & $<0.0004$ & $<0.0004$ & 0.02 \\
Lead & $<0.10$ & 0.26 & $<0.10$ & 2.30 \\
Molybdenum & 0.07 & 0.07 & 0.11 & 1.00 \\
Nickel & $<0.05$ & $<0.05$ & $<0.05$ & 0.44 \\
Selenium & $<0.007$ & $<0.007$ & $<0.007$ & 0.15 \\
Tin & $<0.02$ & $<0.02$ & $<0.02$ & 0.40 \\
Vanadium & $<0.10$ & $<0.10$ & $<0.10$ & 1.80 \\
Zinc & $<0.20$ & $<0.20$ & $<0.20$ & 4.50 \\
Fluoride & 1.2 & 1.2 & 1.4 & 55 \\
Chloride & 60 & 89 & 160 & 616 \\
Sulfate & 38 & 54 & 66 & 2.430 \\
Bromide & 1.0 & 1.1 & 1.6 & 20 \\
\hline
\end{tabular}

All values in $\mathrm{mg} / \mathrm{kg} \mathrm{ds}$. 

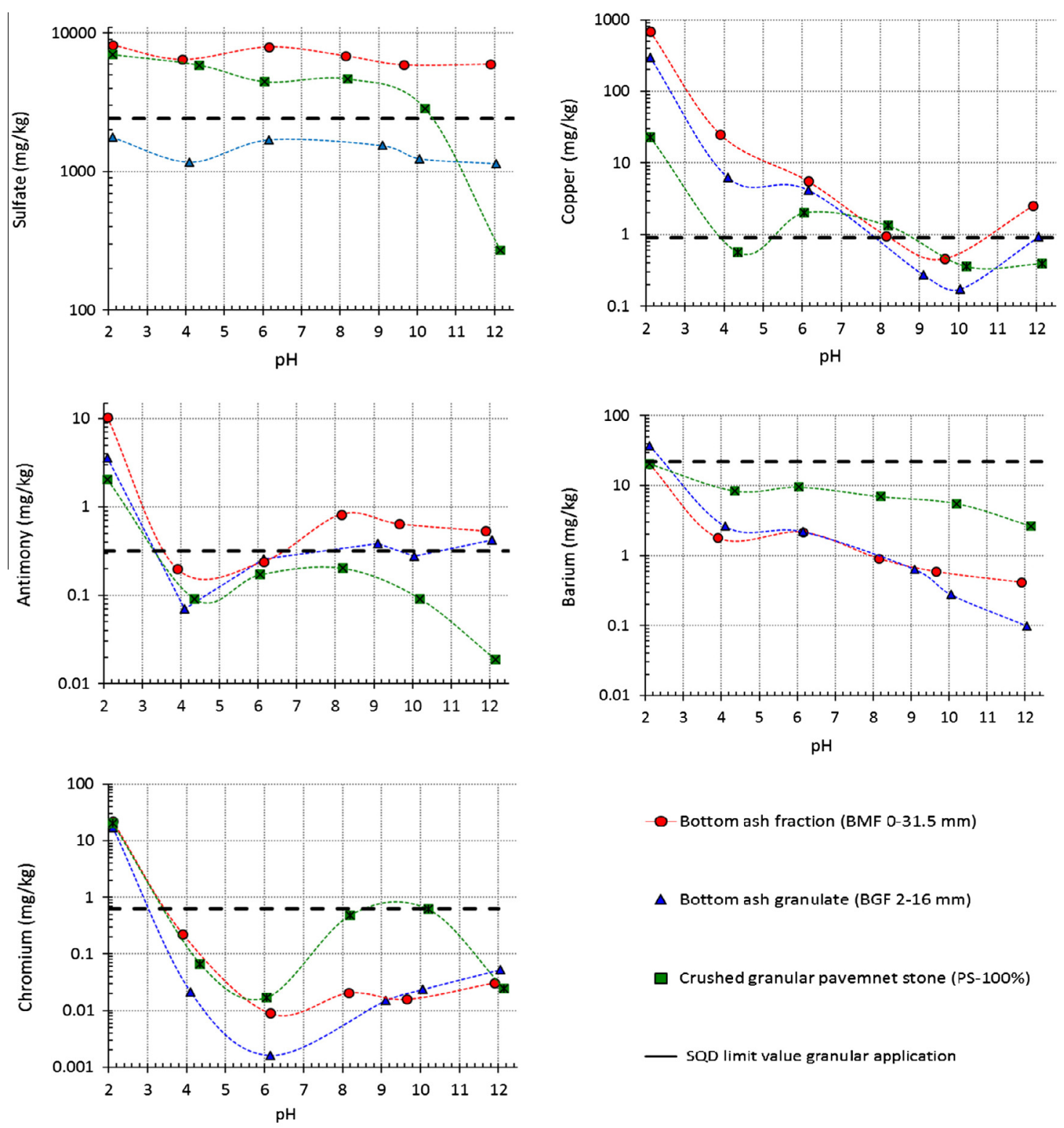

- Bottom ash fraction (BMF 0-31.5 mm)

A Bottom ash granulate (BGF 2-16 mm)

Crushed granular pavemnet stone (PS-100\%)

— SQD limit value granular application

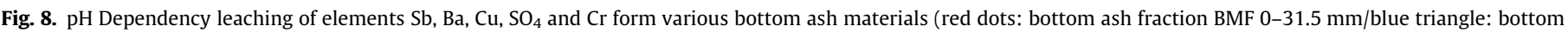

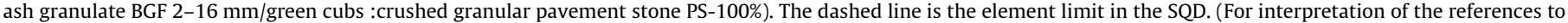
color in this figure legend, the reader is referred to the web version of this article.)

$\mathrm{pH} 12-10$, the increased Ba leaching may also be affected by the dissolution of ettringite from the cementitious matrix, stimulating solubility. Hence, at lower $\mathrm{pH}<10$, barium release further increases and it is assumed that the leaching of Ba is controlled by the solubility of barium sulfate (Sloot et al., 2001; Vollpracht and Brameshuber, 2015).

As for copper, the leaching pattern for all three materials is more or less similar, albeit that the availability of $\mathrm{Cu}$ is substantially lower in the concrete in comparison with the bottom ash. The leaching of $\mathrm{Cu}$ from the bottom ash fractions (BMF and BGF), between $\mathrm{pH} 6$ and 10, is mainly controlled by the formation of copper hydroxide $\left(\mathrm{Cu}(\mathrm{OH})_{2}\right.$, Klemm, 1998) and the complexation to dissolved organic matter (Impellitteri et al., 2002; Meima et al., 2002; Zomeren and Comans, 2004). In addition, the BGF containing concrete seems to indicate a somewhat elevated $\mathrm{Cu}$ release between $\mathrm{pH} 6$ and 10, which is the typical $\mathrm{pH}$ range where the binding of $\mathrm{Cu}$ to organic ligands is important. Possibly, the increased $\mathrm{Cu}$ leaching could be caused by the addition of the organic fatty acid based super plasticizer (SP) during the concrete production process. This SP contains reactive organic molecules with probably a high proportion of negatively charged carboxylic groups. Copper has a high affinity for organic ligand complexes with these carboxylic groups (fulvic acids). Overall, the results show that $\mathrm{Cu}$ leaching of BGF is significantly lower than the regulatory limit value and is strongly reduced compared with that of BMF. This effect is caused by the washing step where a substantial fraction of the dissolved organic carbon (DOC) fraction (humic and fulvic acids) was removed. Pilot results show that DOC reduces more than $50 \%$ from $100-130 \mathrm{mg} / \mathrm{kg} \mathrm{dm}$ from initial BMF input $(2-31.5 \mathrm{~mm}$ ) to $25-50 \mathrm{mg} / \mathrm{kg} \mathrm{dm}$ in the washed BGF $2-16 \mathrm{~mm}$ (mixture of BGF 2-8 $\mathrm{mm}$ and $8-16 \mathrm{~mm}$ ).

The leaching of $\mathrm{Sb}$ from BGF as a function of $\mathrm{pH}$ reflects the typical behavior of an oxyanion with relatively $\mathrm{pH}$ independent leaching at neutral $(\mathrm{pH} 7)$ to alkaline $\mathrm{pH}(12)$, which is opposite of most 
cat-ions (Dijkstra et al., 2006a). Antimony leaching from bottom ash is not yet completely understood. However, multiple possible reaction mechanisms affecting $\mathrm{Sb}$ leaching are described (Cornelis et al., 2012; Dijkstra et al., 2006a) and the extent to which these properties are dominant will most likely determine the net leaching behavior. Dissolved $\mathrm{Sb}$ is assumed to be predominantly $\mathrm{Sb}(\mathrm{V})$ in weathered ashes ( $\mathrm{pH}$ range $8-10)$ and $\mathrm{Sb}(\mathrm{III})$ in fresh produced ashes at $>\mathrm{pH} 10$ (Cornelis et al., 2012). These forms of $\mathrm{Sb}$ behave differently with respect to conditions in the bottom ash, e.g. $\mathrm{pH}, \mathrm{DOC}, \mathrm{Ca}$ and $\mathrm{Fe} / \mathrm{Al}$ containing minerals/oxides (Cornelis et al., 2012; Dijkstra et al., 2006a; Meima and Comans, 1998). Additionally, pH-dependence data for the treated BGF fraction (blue triangle data points) show that the washing and wet separation step strongly reduces $\mathrm{Sb}$ leaching at the natural to moderately high $\mathrm{pH}$ of the bottom ash granulate ( $\mathrm{pH} 8.5-12)$. This result indicates that part of the abundant $\mathrm{Sb}$ in the ash is present in soluble form that is removable by washing techniques. It has been suggested that $\mathrm{Sb}$ (III) can form complexes with DOC in bottom ash (Cornelis et al., 2012; Wilson et al., 2010). It should be noted that the leaching at pH 8.5 can remain critical after wet processing of the bottom ash into BGF.

The leaching of $\mathrm{Sb}$ in concrete seems to be significantly further reduced by cement use. This effect is partly caused by dilution of $50 \%$ of total aggregate replacement. Furthermore, the relatively low Sb leaching at high $>\mathrm{pH} 11$ in concrete seems to indicate that $\mathrm{Sb}$ is incorporated in ettringite or possibly romeite, which is typical for cementitious matrices (Baur et al., 2004; Cornelis et al., 2012; Klemm and Bhatty, 2002; Vollpracht and Brameshuber, 2015). In addition, ettringite and romeite stability is related to $\mathrm{pH}$ and start to dissolve towards lower ( $\mathrm{pH}<10.5$ ). This process can initiate $\mathrm{Sb}$ release (Cornelis et al., 2012; Dijkstra et al., 2006a; Klemm and Bhatty, 2002; Klemm, 1998; Sloot et al., 2001) as seems to be consistent with the results shown in Fig. 8c. In summary, the Sb leaching of BGF is still critical towards the limit values of the SQD, although the emission from crushed concrete is significantly lower than the regulatory limit value.

The availability of sulfate within the bottom ash fractions is substantially reduced by the wet separation step (BGF) and to a lesser extent by dry (BMF) treatment of bottom ash. The sulfate leaching is almost $\mathrm{pH}$ independent over a wide range of $\mathrm{pH}$ values. It has been found that the leaching of sulfate from bottom ash is primarily controlled by the solubility of gypsum (Cornelis et al., 2008; Dijkstra et al., 2006a; Saffarzadeh et al., 2011; Sorlini et al., 2011) and the results in Table 3 are consistent with these observations. Especially for sulfate, the leaching behavior of the concrete differs substantially compared with that of bottom ash. It is assumed that the leaching of sulfate in the concrete is controlled by increasing decomposition of ettringite (between $\mathrm{pH} 10$ and 12 ) and the observed solubility increase results in the release of mono-sulfate (Baur et al., 2004; Christensen et al., 2004; Klemm, 1998; Sloot et al., 2001).

The results of the $\mathrm{pH}$ dependent leaching tests also clearly indicate that the enhanced leaching of sulfate from the bottom ash containing concrete is primarily caused by the concrete and the use of cement (related to anhydrite content of cement used as setting retarder Table 2). However, further quality improvement to reduce $\mathrm{SO}_{4}$ leaching from crushed concrete should aim specifically at the cement, since this material is the main source of sulfate.

The same observation is made for the $\mathrm{pH}$ dependent leaching of chromium (Fig. 8). Untreated and treated bottom ash fractions show a different $\mathrm{Cr}$ leaching pattern, in the $\mathrm{pH}$ range from about $7-11$, in comparison with the BGF containing concrete. The results indicate that $\mathrm{Cr}(\mathrm{VI})$ may be present in the concrete, as was also shown by earlier work on the characterization of cement mortars (Sloot et al., 2001). From this study it was also found that $\mathrm{Cr}$ leaching emissions levels, are related to the cement type that was used.
Pure Portland cement shows the highest $\mathrm{Cr}$ leaching, while blended Portland cements (CEM II and CEM III containing supplementary cementitious materials) show decreasing $\mathrm{Cr}$ levels, all in the $\mathrm{pH}$ range of 7-11 (Sloot et al., 2001). However, the results of the analyzed BGF containing concrete cannot be completely explained based on the results of this research. In this study, a CEM III with a composition of moderate $40-60 \%$ clinker and moderate $60-40 \%$ GGBS was used. This type of cement mortar has shown a relatively low to moderate $\mathrm{Cr}$ leaching $( \pm 0.1$ to $<0.01 \mathrm{mg} / \mathrm{kg}$ at $\mathrm{pH} 5-10$ ), where concentration is related to the clinker content (Sloot et al., 2001). Possibly, the bottom ash can exhibit some oxidizing properties causing the conversion of $\mathrm{Cr}(\mathrm{III})$ to $\mathrm{Cr}(\mathrm{VI})$ in the products. This potential effect should be studied in further work.

To finalize, the leaching behavior as a function of $\mathrm{pH}$ does also indicate possible expected changes in the emission of contaminants in multiple life phases, as the $\mathrm{pH}$ of alkaline materials tends to neutralize as a result of carbonation. This process will proceed much faster when the surface area of the material is increased in the case of granular demolition material. The $\mathrm{pH}$ test can be used as a basis for judgement of potential long-term weathering effects on the emission of contaminants. Further research is necessary to assess the possible scenarios in multiple life phases of construction materials and the expected degree and rate of weathering that will occur. It should be noted that, apart from the assessment of emissions to soil and groundwater, the physical properties of construction materials are also important and can as well contribute to decisions on future applications in multiple life phase.

\section{Conclusions}

A novel treatment process of MSWI bottom ash is developed to gain a higher level of its re-use as secondary granulate material (BGF) within earth-moist cement mixtures. A comprehensive overview demonstrates the production, design and characterization of BGF, e.g. their physical and chemical properties and related performance within a granular (open) and monolithic (concrete) application. This study leads to the following conclusions:

- The design and development of an MSWI bottom ash treatment process should focus fully on the desired granulate (endproduct) properties and its final application, gaining a reliable and optimal performing granulate.

- A wet (water washing) treatment in addition to or compared with dry treatment enables the significant removal of unwanted substances within bottom ash, e.g. soluble salts (chloride and sulfate), heavy metals and organic structures as well as unwanted fine and unburned particles. Additionally, the wet treatment is an ideal process for effectively tuning and adjusting needed BGF particle-size distribution.

- BGF fractions are in compliance with the standard EN 12620 (aggregates for concrete) and do not show large variations when compared with natural aggregates. The physical and chemical properties of BGF differ slightly compared to natural gravel (e.g. lower density material $\pm 2400 \mathrm{~kg} / \mathrm{m}^{3}$ instead of $2600 \mathrm{~kg} /$ $\mathrm{m}^{3}$, higher water absorption; $6.8 \%$ instead of $1.3 \%$, and lower crushing resistance of 31-33 instead of $>35$ (LA index).

- The leaching of BGF 2-8 mm and 8-16 mm were not fully in compliance with the open (granular) application criteria of the Dutch Soil Quality Degree (SQD). Release of chloride and antimony are just above or just below their limit values. An additional wet treatment optimization, e.g. at increased L/S ratio (extracting more soluble salts) and/or the addition of specific additives could further improve their environmental quality to comply with the SQD granular limit value (Comans et al., 2000; Yang et al., 2012). 
- In two cement based earth-most concrete mixtures (pavementand curb stones), coarse natural gravel fractions were replaced up to $100 \%$ with bottom ash granulate. Both mixtures, with increasing BGF contents, maintained necessary fresh and hardened physical and chemical performances, e.g. workability and strength, freeze-thaw limits. A moderate tensile strength increase was observed with higher BGF content within the pavement stone mixtures. Especially the BGF 2-8 mm showed promising results, where the smaller size particles have the tendency to give an overall better performance compared to the larger size fraction size $8-16 \mathrm{~mm}$.

- Replacing BGF up to $100 \%$ for natural gravel did not affect the overall emission and leaching behavior of the monolithic state concrete. The leaching behavior and analyses of granular state, crushed BGF containing concrete, within a second life phase, shows that all measured elements are far below their limit values in accordance with the SQD for granular (open) application.

- An indication of the potential emission of crushed BGF containing concrete within multiple-life phases indicated that the emissions might change in a following life phase due to weathering and carbonation. Rising sulfate $\left(\mathrm{SO}_{4}\right)$, barium (Ba) and chromium $(\mathrm{Cr})$ release (by mineral dissolution and oxidation) where observed at $\leqslant \mathrm{pH} 10.5$. Where $\mathrm{Cr}$ can be attributed to the cement type and $\mathrm{SO}_{4}$ and $\mathrm{Ba}$ to overall cement use; the elements are not related to the BGF content.

\section{Acknowledgements}

The authors wish to express their gratitude to Van Gansewinkel Minerals and De Hamer (part of the BTE Group) for supporting this research. We especially appreciate all the people who have helped during both pilots of the granulate production and concrete element production.

\section{References}

Soil Quality Degree [WWW Document], 2015. <http://wetten.overheid.nl/ BWBR0022929/geldigheidsdatum_14-12-2015> (accessed 12.14.15).

Abbà, A., Collivignarelli, M.C., Sorlini, S., Bruggi, M., 2014. On the reliability of reusing bottom ash from municipal solid waste incineration as aggregate in concrete. Compos. Part B Eng. 58, 502-509.

Aberg, A., Kumpiene, J., Ecke, H., 2006. Evaluation and prediction of emissions from a road built with bottom ash from municipal solid waste incineration (MSWI). Sci. Total Environ. 355, 1-12.

Aguiar, M., Calmano, W., Ecke, H., 2009. Wet extraction of heavy metals and chloride from MSWI and straw combustion fly ashes. Waste Manage. 29, 2494 2499.

Allegrini, E., Maresca, A., Olsson, M.E., Holtze, M.S., Boldrin, A., Astrup, T.F., 2014. Quantification of the resource recovery potential of municipal solid waste incineration bottom ashes. Waste Manage. 34, 1627-1636.

Arickx, S., De Borger, V., Van Gerven, T., Vandecasteele, C., 2010. Effect of carbonation on the leaching of organic carbon and of copper from MSWl bottom ash. Waste Manage. 30, 1296-1302.

Baur, I., Keller, P., Mavroccordatos, D., Wehrli, B., Johnson, C.A., 2004. Dissolutionprecipitation behaviour of ettringite, monosulfate and calcium silicate hydrate. Cem. Concr. Res.

Bertolini, L., Carsana, M., Cassago, D., Collepardi, M., Curzio Curzio, A., 2004. Bottom ash of municipal solid wastes from incineration plant as mineral additions in concrete.

Biganzoli, L., Ilyas, A., Praagh, M.Van, Persson, K.M., Grosso, M., 2013. Aluminium recovery vs. hydrogen production as resource recovery options for fine MSWl bottom ash fraction. Waste Manage. 33, 1174-1181.

BRL 2507 AEC granulaat als toeslagmateriaal voor beton, 2013.

Chang, F.Y., Wey, M.Y., 2006. Comparison of the characteristics of bottom and fly ashes generated from various incineration processes. J. Hazard. Mater. 138, 594-603.

Cheung, J., Jeknavorian, A., Roberts, L., Silva, D., 2011. Impact of admixtures on the hydration kinetics of Portland cement. Cem. Concr. Res. 41, 1289-1309.

Chimenos, J.M., Fernández, A.I., Miralles, L., Segarra, M., Espiell, F., 2003. Short-term natural weathering of MSWI bottom ash as a function of particle size. Waste Manage. 23, 887-895.

Chimenos, J.M., Segarra, M., Fernandez, M.A., Espiell, F., 1999. Characterization of the bottom ash in municipal solid waste incinerator. J. Hazard. Mater.
Christensen, A.N., Jensen, T.R., Hanson, J.C., 2004. Formation of ettringite AFt, and monosulfate AFm in hydrothermal hydration of Portland cement and of calcium aluminum oxide-calcium sulfate dihydrate mixtures studied by in situ synchrotron X-ray powder diffraction. J. Solid State Chem. 177, 1944-1951.

Cioffi, R., Colangelo, F., Montagnaro, F., Santoro, L., 2011. Manufacture of artificial aggregate using MSWI bottom ash. Waste Manage. 31, 281-288.

Comans, R.N.J., Meima, J.A., Geelhoed, P.A., 2000. Reduction of contaminant leaching from MSWI bottom ash by addition of sorbing components. Waste Manage. 20, 125-133.

Cornelis, G., Johnson, C.A., Van Gerven, T., Vandecasteele, C., 2008. Leaching mechanisms of oxyanionic metalloid and metal species in alkaline solid wastes: a review. Appl. Geochem. 23, 955-976.

Cornelis, G., Van Gerven, T., Vandecasteele, C., 2012. Antimony leaching from MSW bottom ash: modelling of the effect of $\mathrm{pH}$ and carbonation. Waste Manage. 32, $278-286$.

Dijkstra, J.J., Van Der Sloot, H.A., Comans, R.N.J., 2006a. The leaching of major and trace elements from MSWI bottom ash as a function of $\mathrm{pH}$ and time. Appl. Geochem. 21, 335-351.

Dijkstra, J.J., Van Zomeren, A., Meeussen, J.C.L., Comans, R.N., 2006b. Effect of accelerated aging of MSWI bottom ash on the leaching mechanisms of copper and molybdenum. Environ. Sci. Technol. 40, 4481-4487.

van Eijk, R.J., 2001. Hydration of Cement Mixtures Containing Contaminants.

Florea, M.V.A., 2014. Secondary materials applied in cement-based products: treatment, modelling and environmental interaction. CIP-DATA Library Technische Universiteit Eindhoven, Eindhoven.

Forteza, R., Segui, C., Cerda, V., 2004. Characterization of bottom ash in municipa solid waste incinerators for its use in road base. Waste Manage. 24, 899-909.

Funari, V., Braga, R., Bokhari, S.N.H., Dinelli, E., Meisel, T., 2014. Solid residues from Italian municipal solid waste incinerators: a source for "critical" raw materials. Waste Manage. 45, 206-216.

Gougar, M.L.D., Scheetz, B.E., Roy, D.M., 1996. Ettringite and C-S-H Portland cement: phases for waste ion immobilization: a review. Waste Manage. 16, 295-303.

Hassan, M.M., Khalid, H., 2010. Mechanical and environmental characteristics of bituminous mixtures with incinerator bottom ash aggregates. Int. J. Pavement Eng. 11, 83-94.

Hu, B., Rem, P., Van De Winckel, T., 2008. Fine heavy non-ferrous and precious metals recovery in bottom ash treatment.

Hüsken, G., Brouwers, H.J.H., 2008. A new mix design concept for earth-moist concrete: a theoretical and experimental study. Cem. Concr. Res. 38, 12461259.

Impellitteri, C.A., Lu, Y., Saxe, J.K., Allen, H.E., Peijnenburg, W.J.G.M., 2002 Correlation of the partitioning of dissolved organic matter fractions with the desorption of $\mathrm{Cd}, \mathrm{Cu}, \mathrm{Ni}, \mathrm{Pb}$ and $\mathrm{Zn}$ from 18 Dutch soils. Environ. Int. 28, 401410.

Jani, Y., Hogland, W., 2014. Waste glass in the production of cement and concrete a review. J. Environ. Chem. Eng. 2, 1767-1775.

Klemm, W.A., 1998. Ettringite and oxyanion substituded ettringites-their characterization and applications in the fixation of heavy meatals: a synthesis of the literature.

Klemm, W.A., Bhatty, J.I., 2002. Fixation of Heavy Metals as Oxyanion-Substituted Ettringites. Skokie, IL USA.

Kuo, W., Liu, C., Shu, C., 2015. The feasibility of using washed municipal solid waste incinerator bottom ash in compressed mortar paving units. J. Mar. Sci. Technol 23, 364-372.

Kuo, W.-T., Liu, C.-C., Su, D.-S., 2013. Use of washed municipal solid waste incinerator bottom ash in pervious concrete. Cem. Concr. Compos. 37, 328335.

Lin, Y.-C., Panchangam, S.C., Wu, C.-H., Hong, P.-K.A., Lin, C.-F., 2011. Effects of water washing on removing organic residues in bottom ashes of municipal solid waste incinerators. Chemosphere 82, 502-506.

Margallo, M., Taddei, M.B.M., Hernández-pellón, A., Aldaco, R., Irabien, Á., 2015 Environmental sustainability assessment of the management of municipal solid waste incineration residues: a review of the current situation. Clean Technol. Environ. Policy 17, 1333-1353.

Meima, J.A., Comans, R.N.J., 1999. The leaching of trace elements from municipal solid waste incinerator bottom ash at different stages of weathering. Appl. Geochem. 14, 159-171.

Meima, J.A., Comans, R.N.J., 1998. Reducing Sb-leaching from municipal solid waste incinerator bottom ash by addition of sorbent minerals. J. Geochem. Explor. 62, 299-304

Meima, J.A., van der Weijden, R.D., Eighmy, T.T., Comans, R.N.J., 2002. Carbonation processes in municipal solid waste incinerator bottom ash and their effect on the leaching of copper and molybdenum. Appl. Geochem. 17, 1503-1513.

Müller, U., Rübner, K., 2006. The microstructure of concrete made with municipal waste incinerator bottom ash as an aggregate component. Cem. Concr. Res. 36, $1434-1443$.

Oehmig, W.N., Roessler, J.G., Blaisi, N.I., Townsend, T.G., 2015. Contemporary practices and findings essential to the development of effective MSWI ash reuse policy in the United States. Environ. Sci. Policy 51, 304-312.

Paoletti, F., Sirini, P., Seifert, H., Vehlow, J., 2001. Fate of antimony in municipal solid waste incineration. Chemosphere 42, 533-543.

Pera, J., Cautaz, L., Ambroise, J., Chababbet, M., 1997. Use of incinerator bottom ash in concrete. Cem. Concr. Res. 27, 1-5.

Piantone, P., Bod, F., Chatelet-snidaro, L., 2004. Mineralogical study of secondary mineral phases from weathered MSWI bottom ash: implications for the modelling and trapping of heavy metals. Appl. Geochem. 19, 1891-1904. 
Rem, P.C., De Vries, C., van Kooy, L.A., Bevilacqua, P., Reuter, M.A., 2004. The Amsterdam pilot on bottom ash. Miner. Eng. 17, 363-365.

Rubner, K., Haamkens, F., Linde, O., 2008. Use of municipal solid waste incinerator bottom ash as aggregate in concrete. Q. J. Eng. Geol. Hydrogeol. 41, 459-464.

Saffarzadeh, A., Shimaoka, T., Wei, Y., Gardner, K.H., Musselman, C.N., 2011. Impacts of natural weathering on the transformation/neoformation processes in landfilled MSWI bottom ash: a geoenvironmental perspective. Waste Manage. $31,2440-2454$

Shim, Y., Kim, Y., Kong, S., Rhee, S., Lee, W., 2003. The adsorption characteristics of heavy metals by various particle sizes of MSWI bottom ash. Waste Manage. 23, 851-857.

Sloot, H.A. van der, Hoede, D., Rietra, R.P.J.J., Stenger, R., Lang, Th., Schneider, M., Spanka, G., Stoltenberg-Hansson, A., Laret, A., 2001. Environmetal Criteria for Cement Based Products (ECRICEM), Report C-01-069. Petten, The Netherlands.

Sorlini, S., Abbà, A., Collivignarelli, C., 2011. Recovery of MSWI and soil washing residues as concrete aggregates. Waste Manage. 31, 289-297.

Stegemann, J.A., Schneider, J., Baetz, B.W., Murphy, K.L., 1995. Lysimeter washing of MSW incinerator bottom ash. Waste Manage. Res. 13, 149-165.

Syahrul, M., Sani, M., Muftah, F. Muda, Z., 2010. The properties of special concrete using washed bottom ash (WBA) as partial sand replacement. Int. J. Sustain. Constr. Eng. Technol. 1, 65-76.

Tang, P., Florea, M.V.a., Spiesz, P., Brouwers, H.J.H., 2015. Characteristics and application potential of municipal solid waste incineration (MSWI) bottom ashes from two waste-to-energy plants. Constr. Build. Mater. 83, 77-94.
Toraldo, E., Saponaro, S., Careghini, A., Mariani, E., 2013. Use of stabilized bottom ash for bound layers of road pavements. J. Environ. Manage. 121, 117-123.

Vítková, M., Ettler, V., Sebek, O., Mihaljevic, M., Grygar, T., Rohovec, J., 2009. The pHdependent leaching of inorganic contaminants from secondary lead smelter fly ash. J. Hazard. Mater. 167, 427-433.

Vollpracht, A., Brameshuber, W., 2015. Binding and leaching of trace elements in Portland cement pastes. Cem. Concr. Res. 79, 76-92.

Wilson, S.C., Lockwood, P.V., Ashley, P.M., Tighe, M., 2010. The chemistry and behaviour of antimony in the soil environment with comparisons to arsenic: a critical review. Environ. Pollut. 158, 1169-1181.

Yang, R., Liao, W.-P., Wu, P.-H., 2012. Basic characteristics of leachate produced by various washing processes for MSWI ashes in Taiwan. J. Environ. Manage. 104, 67-76.

Yu, R., Tang, P., Spiesz, P., Brouwers, H.J.H., 2014. A study of multiple effects of nanosilica and hybrid fibres on the properties of Ultra-High Performance Fibre Reinforced Concrete (UHPFRC) incorporating waste bottom ash (WBA). Constr. Build. Mater. 60, 98-110.

Zevenbergen, C., Van Reeuwijk, L.P., Bradley, J.P., Bloemen, P., Comans, R.N.J., 1996. Mechanism and conditions of clay formation during natural weatering of MSWI bootom ash. Clays Clay Miner. 44, 546-552.

Zhang, T., Zhao, Z., 2014. Optimal use of MSWI bottom ash in concrete. Int. J. Concr. Struct. Mater. 8, 173-182.

Zomeren, A. Van, Comans, R.N.J., 2004. Contribution of Natural Organic Matter to Copper Leaching from Municipal Solid Waste Incinerator. Environ. Sci. Technol. 38, 3927-3932. 